\title{
El encuentro y la duración del amor en Criba de Julián Pérez $^{1}$
}

\section{The finding and duration of love in Criba, by Julián Pérez}

\author{
Amancio Edison Flores Muñoz ${ }^{2}$ \\ Universidad Nacional Mayor de San Marcos. Lima, Perú \\ amancio_efm@hotmail.com \\ ORCID 0000-0002-4706-5392
}

Citar como: Flores, A. (2019). El encuentro y la duración del amor en Criba de Julián Pérez. Desde el Sur, 11(2), pp. 201-216.

\section{RESUMEN}

El presente artículo tiene como objetivo indagar en la representación del «amor» en la novela Criba (2013), del escritor peruano Julián Pérez. Por eso, se recoge los aportes filosóficos de Alain Badiou, a fin de interpretar, desde una hermenéutica literaria, la producción de la «verdad» que adviene del «encuentro» y la «duración» del amor en la «escena del Dos», donde participan los personajes Evangelina Delgadillo y Manuel Bajalqui. En la misma orientación, aunque con énfasis en los trabajos metatextuales que han subrayado la importancia del amor y el sexo en la producción literaria del escritor Julián Pérez, se propone un análisis que considere al amor como la aceptación de las diferencias desde la propuesta de Badiou.

\section{PALABRAS CLAVE}

Amor, disyunción, escena del Dos, encuentro, duración, verdad, narrativa peruana

\footnotetext{
1 Este artículo es producto de la investigación para la tesis de maestría desarrollada con el fin de obtener el grado de magíster en Literatura Peruana y Latinoamericana por la Universidad Nacional Mayor de San Marcos (UNMSM).

2 Licenciado en Literatura por la Universidad Nacional Federico Villarreal (UNFV). Candidato a Magister en Literatura Peruana y Latinoamericana por la UNMSM. Egresado del doctorado en Humanidades de la UNFV. Ha participado como ponente en diversos eventos académicos, entre los que destacan las Jornadas Andinas de Literatura Latinoamericana (JALLA 2016, Bolivia), las Jornadas Andinas de Literatura Latinoamericana (JALLA 2018, Brasil) y la II Jornada de Investigaciones Literarias Iberoamericanas (LIBERA).
} 


\section{ABSTRACT}

The aim of this article is to investigate the depiction of "love» in the novel Criba (2013) by the Peruvian writer Julián Pérez. To this end, the philosophical work of Alain Badiou is employed in order to interpret, from a literary hermeneutics perspective, the "truth" that emerges from the "finding" and "duration» of love in the "escena del Dos", in which the characters Evangelina Delgadillo and Manuel Bajalqui participate. In the same vein, although this time with an emphasis on the metatextual studies that have underlined the importance of love and sex in the work of the writer Julián Pérez, we offer an analysis that considers love as the acceptance of differences, echoing the reflections of Badiou.

\section{KEYWORDS}

Love, disjunction, escena de Dos, finding, duration, truth, Peruvian narrative

\section{El amor en la filosofía de Alain Badiou}

La creencia de que el amor es un sentimiento capaz de elevar a los amantes por los cielos, pero también arrojarlos a la oquedad más profunda de la tierra, constituye una de las tantas causas que ha convertido al amor, en el siglo XXI, en una forma de riesgo del cual, si uno es inteligente, debe evitar para no salir mascullado o herido. Idea en la que adviene una serie de inconsistencias, como la consideración de que es posible amar sin riesgo ${ }^{3}$. Posición que, desde luego, niega toda forma de experiencia donde los amantes, a partir de un encuentro azaroso, acceden a un conocimiento del mundo hasta ese entonces desconocido.

Es Platón, sostiene el filósofo francés Alain Badiou, quien confiere al amor un elemento de universalidad, puesto que identifica en la experiencia amorosa un impulso hacia la Idea. Esta se produce, incluso, cuando una persona observa un cuerpo hermoso indistintamente de su fin y con ello accede a lo Bello. Por eso, Badiou encuentra en Platón y, particularmente,

3 Con respecto a unos anuncios publicitarios que cubrieron las calles de París, donde el sitio de web Meetic ofertaba un servicio de encuentro de parejas sin riesgo, el filósofo francés Alain Badiou (2011, p. 18) sostiene lo siguiente: «Pienso que esta publicidad deriva de una consideración asegurador del «amor». Es el amor asegurado a todo riesgo: usted se enamorará, pero tendrá bien calculado el asunto y habrá seleccionado con antelación a su pareja tecleando en Internet». Esta forma de concebir el amor presupone alcanzar los beneficios del encuentro amoroso sin verse afectado por el riesgo del amor mismo, en ese sentido, es una idea, como diría el también filósofo y ensayista Slavoj Žižek, del amor descafeinado, es decir, del amor cero riesgo. 
en la lectura de Fedro un antecedente del amor como acceso a la singularidad. Sobre este punto, Milena Lozano sostiene que «el amor puede ser un acceso a la verdad, sea esta una verdad trascendente como en Platón, o inmanente a nuestro mundo como propone Badiou» (2014, p. 205). Es decir, existe una universalidad en el encuentro amoroso, pero sometido a una humanidad ${ }^{4}$ material.

Entonces, lo primero a considerar cuando se discurre en el tema del amor - al menos desde la perspectiva de esta investigación - es que dicha categoría permite el acceso a una verdad o un conocimiento del mundo desde la mirada de las diferencias y no solamente de la identidad. En ese sentido, «es en el amor donde el sujeto va más allá de sí mismo, más allá del narcisismo» (Badiou, p. 31, 2011). Es dentro de esta orientación que el autor de El ser y el acontecimiento subraya la importancia de la tesis de Jacques Lacan, quien sostenía que la relación sexual no existe porque en la sexualidad cada uno de los amantes va por su lado. El goce nunca es compartido por el otro; antes bien, lo aleja del ser amado. Si no existe relación sexual, es el amor el encargado de suplirla. La confusión de esta aseveración lacaniana surge al considerar que el amor es una «relación» que exige la sustitución del vacío que deja la ausencia del sexo en la unión de los cuerpos. El amor, desde el punto de vista del «encuentro» o el «acontecimiento», es «una producción de verdad. ¿Verdad sobre qué? Sobre lo que lo Dos, y no solo lo Uno, opera en la situación» (Badiou, 2002, p. 244).

Otra aspecto a considerar es que el amor es una separación o disyunción de la experiencia de dos personas (posición mujer y posición hombre) que con su modo particular de ver el mundo y con toda su infinita subjetividad jamás acceden al otro. En ese sentido, las dos posiciones están disyuntas por la distancia que confiere la presencia del Dos. «No hay presentación afectada a mujer y presentación afectada a hombre, y después zonas de coincidencia o intersección» (Badiou, p. 245, 2002). ¿Qué permite entonces que de la disyunción del amor advenga una experiencia nueva de la realidad si se está ante dos especies distintas? Para Badiou, la presentación del Dos se da a conocer con el «encuentro». Dicho de otra manera, «el amor se inicia siempre con un encuentro, al que yo le otorgo la categoría, de alguna forma metafísica, de acontecimiento. Es decir, algo que no entra en la ley inmediata de las cosas» (Badiou, p. 42, 2011). Ya en el Lógicas de los mundos: el ser y el acontecimiento 2, Alain Badiou sostiene

4 Alain Badiou (2002, p. 246) entiende por humanidad «lo que hace de soporte para los procedimientos genéricos, o procedimientos de verdad: la ciencia, la política, el arte y — justamente- el amor [...] La humanidad es lo que sostiene la singularidad infinita de las verdades que se inscriben en estos tipos. La humanidad es el cuerpo historial de las verdades». 
que «el acontecimiento (el encuentro amoroso) hace surgir una escena del Dos, cuyo enunciado es que hay algo en común entre esas dos especies diferentes, un objeto universal, del que uno y otro participan» (2008, p. 92).

La literatura ha representado dicha «disyunción» y dicho «encuentro» donde los amantes a veces no pertenecen a la misma clase social, a los mismos clanes o los mismos grupos políticos, pero gracias al milagroso acontecimiento son capaces de traspasar sus subjetividades a fin de poner en marchar el amor. Un ejemplo de esto es Romeo y Julieta, donde los amantes son capaces de atravesar la potencia de sus dualidades y con ello acceden al encuentro del amor. Casualmente lo que permite la aparición del acontecimiento amoroso es la radical diferencia de los amantes. Hay dos posiciones disyuntas, formas particulares de ver el mundo, de sentirlo, de abrazarlo: una es Capuleto; el otro, Montescos. Pero, a pesar de la inconmensurable distancia que los separa, de los odios y rencores heredaros, ambos persisten en declarar el amor bajo el enunciado «te amo».

Habría que precisar ahora cómo dos posiciones negadas a ser contadas e imposibilitadas de transferir su experiencia del mundo (su conciencia) logran convertirse en un universal para todos. Para que exista disyunción y, a la vez, advenga la verdad es necesario considerar al amor como un proceso, un trayecto, un trabajo, es decir, la suposición de que hay un Dos (Badiou, 2002, pp. 249-250). Es claro que la escena del Dos no es un ser del Dos dado que nunca se accede la subjetivad del otro. Mejor dicho, y siguiendo los postulados de la filosofía del lenguaje, la conciencia nunca es individual sino colectiva, pero esto es solo por la mediación de lenguaje y no porque se constituya una nueva identidad, un Tres. Lo que Alain Badiou evidencia en su filosofía del amor es el impasse de la identidad y la alteridad, $y$, ante ello, formula la posibilidad de acceder a la verdad en el vacío de esa inconsistencia a través de la intervención de un «sujeto» que declare el amor como un enunciado de «verdad»:

¿Cuál es el vacío aquí convocado por la declaración de amor? Es el vacío, in-sabido, de la disyunción. La declaración del amor pone en circulación en la situación un vocablo extraído del intervalo nulo que disyunta las posiciones hombre y mujer. «Yo te amo» reúne dos pronombres, yo, tú, que son imposibles de unir puesto que son reenviados a la disyunción. La declaración fija nominalmente el encuentro como tenido por ser el vacío de la disyunción. El Dos que amorosamente opera es propiamente el nombre de lo disyunto aprehendido en su disyunción (Badiou, p. 250, 2002).

Lo dicho por Badiou resulta significativo porque es la fidelidad a la declaración del amor, esa eterna persistencia a la nominación surgida del 
vacío de la situación, aquella que permite acceder a la verdad del amor. En ese sentido, el amor entendido como un acontecimiento convoca dos subjetividades que comparten «la escena del Dos» desde el momento en que sus condiciones actuales (psicológicas, existenciales, culturales y sociales) se ven reorganizadas en post de un nuevo presente que fractura su relación con el mundo hasta ese entonces conocido por los amantes. A través de la aparición del acontecimiento, los individuos, que hasta ese entonces no eran más que cuerpos e identidades, se conviertan en sujetos capaces de exceder los saberes y opiniones de la situación. Habría que precisar que al ser el amor un procedimiento material es necesario que se evalúe constantemente la totalidad de la experiencia y que también se la ponga a prueba. «Porque el amor, después de todo, es algo que tiene que ver con el mundo» (Badiou, p. 45, 2011).

Lo último que debe considerarse con respecto al amor es su «duración». Ya se dijo que el amor es una construcción del mundo desde el punto de vista del Dos. En ese sentido, su producción de verdad está vinculada a decisiones y pruebas como el nacimiento de los hijos, la convivencia familiar, la rutina o el agotamiento del sexo. Acá el término duración no significa que se perpetúa el Dos o que se ame para siempre, sino a que el amor «inventa una forma diferente de durar en la vida» (Badiou, 2011, p. 47). En esta forma de durar en la vida, el amor se reinventa y atestigua que es algo más que una declaración de los amantes. Como muy bien señala Badiou, en la «escena del Dos» los amantes reconocen la huella del acontecimiento y esta los lleva a declararla como una verdad. Pero no solo basta con eso, sino que también la verdad debe someterse a prueba, porque es una singularidad que emerge del «estado de la situación» $u$ «orden simbólico», incluso, el sujeto de verdad cuando aparece se encuentra atravesado por las opiniones. Cabría decir entonces que en el amor los sujetos de amor deben redeclarar constantemente el acontecimiento, sobre todo, porque «las dificultades del amor no están en absoluto relacionadas con la existencia de un enemigo identificado» (Badiou, 2011, p. 77). O para ser más claro: si existe un peligro que acecha al amor este es principalmente intrínseco, producto de la puesta en marcha del proceso. En otras palabras, «el principal enemigo de mi amor, al que debo vencer, no es el otro; soy yo; el "yo" que busca la identidad sobre la diferencia» (Badiou, 2011, p. 79).

\section{Entre el amor y la sexualidad en la narrativa de Julián Pérez}

Entre los muchos aportes que la crítica literaria peruana ha señalado sobre la narrativa de Julián Pérez, hay uno en especial que merece atención porque revela por las razones equivocadas un mérito sobresaliente en el tratamiento del amor. Son muchos los críticos que han subrayado la 
importancia del sexo y el amor en la novela Retablo (2003), desde Carmen Ollé, que repara en el enfoque erótico en relación con la mujer, pasando por Ricardo González Vigil, que suscribe la afirmación de esta autora, hasta el comentario de Miguel Gutiérrez, que ofrece una explicación más detallada de este tema. Por la amplitud del trabajo del autor de La violencia del tiempo, esta investigación centra su atención en el análisis que se formula en el texto El pacto con el diablo.

Miguel Gutiérrez (2007) sostiene con respecto al tratamiento del amor, el sexo y el erotismo en la novela Retablo que ese tema adquiere, en la ficción de Julián Pérez, una liberación y ampliación dentro de la narrativa indigenista hasta entonces no vista. Recuerda que en la tradición indigenista anterior a Ciro Alegría y José María Arguedas solo existía la «sexualidad inmediata» producto de las vejaciones y violaciones del gamonal en contra de las indias. El sexo no era el disfrute de las partes, sino una manera de cómo se manifestaba el poder del blanco sobre el campesino. Por otro lado, y en un viraje distinto, añade que en Ciro Alegría el amor y el sexo surgen de las uniones placenteras ligadas a ceremonias de enamoramientos; además, tienen un carácter festivo vinculados a la tierra y a la agricultura, incluso en uno de sus relatos - «Siempre hay caminos»-, «el tema central es el deseo y el nacimiento del amor erótico» (Gutiérrez, p. 433, 2007). Sobre José María Arguedas, Miguel Gutiérrez menciona que en las obras de este autor las relaciones sexuales fluctúan entre «sexo pecaminoso, sucio y culposo (como el que practican los adolescentes de Los ríos profundos con la opa o don Bruno con Kurku en Todas las sangres) y el sexo sublimado por una suerte de amor romántico que se da entre el mundo de los mistis o entre el señor y la mestiza» (pp. 433-434).

En el caso de Eleodoro Vargas Vicuña, Gutiérrez agrega que su representación del amor y el sexo está ligado a los ritos agrarios y a la estaciones, así como, en algunas ocasiones, al incesto. Todas estas situaciones son narradas con lenguaje afectado de un profundo lirismo que en la obra de este escritor resulta un rasgo distintivo. En resumidas cuentas, lo que saca en limpio, luego de esta somera descripción del tópico del amor y el sexo, es que en la narrativa indigenista y posarguediana ese tópico es abordado de manera «esquemática, austera, casi pudibunda» (p. 434).

Es en ese contexto donde la publicación de Retablo aparece como una novela cuyo tratamiento del amor y el sexo amplía y renueva las formas representación de este tópico. En la novela de Julián Pérez, menciona Miguel Gutiérrez, aparecen diversos tipos de amor y una predisposición al goce al que se entregan, sin distinción, hombres y mujeres. En definitiva, es un «erotismo celebratorio, lúdico, picaresco y libre» (p. 434), y su desenvolvimiento ocurre en la zonas más rurales. 
Lo mencionado por Miguel Gutiérrez, sobre la ampliación o tratamiento del amor y el sexo en la novela Retablo de Julián Pérez, resulta ilustrativo porque evidencia un problema recurrente en el análisis de ese tópico por la crítica literaria, no solo en la narrativa indigenista, sino también en la literatura en general. Este impasse surge porque en los análisis de la representación del amor en la narrativa $-\mathrm{y}$, por qué no, en la poesía- se parte de la premisa de que el «amor» y el «sexo» son dos conceptos irremediablemente inseparables. No obstante, desde una reflexión filosófica vinculada a la verdad como sustracción del aparecer se podría replantear esa relación y encontrar algunas singularidades que ayuden a esclarecer ese vínculo o al menos mostrar caminos distintos en el estudio del amor y la literatura.

Como se mencionó en líneas anteriores, el análisis de Miguel Gutiérrez acerca del tópico del amor y el sexo en la novela Retablo fue suscrito por más de un reseñista o comentarista a la hora de formular alguna interpretación sobre las obras de Julián Pérez. Esto no tendría nada de extraño si no fuera porque en dicho análisis se incide en engarzar amor y sexo como si uno no existiera sin el otro. La novela de Julián constituiría un logro indiscutible en la representación del universo andino porque abordaría, al parecer, la relación sexo, amor y erotismo como una tríada necesaria para repensar las relaciones sexuales en el mundo andino. Si anterior a la tradición arguediana -indianista en términos de Tomás Escajadillo- el sexo era una consecuencia natural del ejercicio del poder del blanco sobre las indias, esta práctica solo permitía reforzar la identidad del sujeto criollo, quien en ese acto reaseguraba su posición dentro del orden simbólico.

Es evidente que, en este escenario, el erotismo no es necesario. Podría indicarse entonces que el sexo, desligado del amor, es siempre narcisista y opera en pos del sometimiento y la dominación del otro. Siendo esto así, ¿cómo el tratamiento del sexo podría ser considerado un elemento importante a la hora de abordar el amor en la narrativa indigenista o cualquier forma artística? No cabe duda de que se está ante una situación donde es necesario esclarecer cuál es el papel del sexo en la producción o proceso del amor y ver si efectivamente, como se infiere de la lectura de Miguel Gutiérrez, en la narrativa indigenista el sexo organiza la representación del amor.

Miguel Gutiérrez también menciona que el tratamiento del amor adquiere una dimensión distinta con Ciro Alegría y José María Arguedas. Un primer problema, aunque no asociado al centro de atención de este artículo, es que para Miguel Gutiérrez el indigenismo se organiza a partir de la aparición de los dos autores mencionados. Habla, como ya se dijo, de un antes y un después a Ciro Alegría y José María Arguedas, evidenciando 
una lectura fijada en nombres y no en transformaciones, sobre todo cuando se discurre en la tradición indigenista. Considerando lo dicho y suscribiendo de nuevo la tipología de Tomás Escajadillo, tanto el autor de El mundo es ancho y ajeno como el de Los ríos profundos pertenecerían al indigenismo ortodoxo y al neoindigenismo, respectivamente. De vuelta al tema del amor, el segundo problema radicaría en que, si bien dentro del estas dos modalidades del indigenismo - sobre todo en Ciro Alegría-, el sexo ya no es producto de las violaciones del gamonal o de «la sexualidad inmediata", sino de uniones placenteras antecedidas por cortejos y situaciones eróticas, sin embargo, de nuevo hay una incidencia en el placer y el deseo para definir el amor. El problema radica en que no se muestra otra dimensión del amor que traspase el sexo y el deseo. El amor no solo es cortejo y seducción orientados a alcanzar el acto coital, porque de reducirse a eso los amantes terminarían recluidos a su mismidad o animalidad instintiva. Es por eso que esta dimensión del amor en la narrativa indigenista es insuficiente para ser considerada como una verdadera ruptura en el tratamiento del amor en la literatura.

Para Miguel Gutiérrez, el tratamiento del amor en la novela Retablo presenta una ampliación de ese tópico porque aparece en esta una mayor predisposición al goce y al placer tanto por hombres como por mujeres del mundo andino. En otras palabras, la representación del sexo y el amor adquiere una dimensión distinta en comparación a las novelas de Ciro Alegría y José María Arguedas, porque desmentiría la visión reducida del sexo que se tenía de los habitantes de los Andes, quienes ahora se arrojan a un erotismo celebratorio y libre. Otro aspecto importante para Miguel Gutiérrez es que esta novela aborda las distintas formas de amor (el amor recatado, el amor no correspondido, el amor filial y el amor afectado por la infidelidad) y las vincula a los procesos sociales e históricos. Este trabajo acepta que, efectivamente, la obra de Julián Pérez en el nivel de la representación del mundo andino aporta un tratamiento distinto del amor y el sexo que resulta un logro considerando la manera como fueron abordados en la tradición indigenista. No obstante, abordarlos (el sexo y el amor) desde la ampliación de un marco referencial tradicional no significa necesariamente una ruptura o una visión distinta del mundo; por el contrario, la incidencia del sexo para definir el amor no hace sino recordar que a veces la lectura crítica de los estudiosos está anclada en los saberes y las opiniones ya establecidos: ese saber que prioriza la identidad sexual sobre las diferencias. La lectura de Miguel Gutiérrez no se sustrae a dicha afirmación.

Si la representación del amor que prioriza la gradación del acto sexual como indicador de logro y ampliación del mundo andino es insuficiente para considerarlo como un criterio afirmativo de la escena del Dos, ¿qué 
debe tomarse en cuenta para brindar un carácter singular o universal al amor? El siguiente acápite busca brindar respuestas a esta interrogante a partir del análisis de la novela Criba de Julián Pérez.

\section{La singularidad del amor en la novela Criba, de Julián Pérez}

\subsection{Manuel Bajalqui y Evangelina Delgadillo}

La representación del amor en la novela Criba de Julián Pérez resulta un logro mayúsculo porque plantea una forma singular de abordarlo sin caer en situaciones comunes, como es el caso de la incidencia en las relaciones sexuales o la liberación del erotismo pudibundo del hombre andino. En el caso de esta novela, en particular, el amor es concebido como el acceso a una verdad desde la mirada de las diferencias y no solo de la identidad. Para comprobar esta idea cuyo marco conceptual recoge los aportes de la teoría del amor de Badiou, se presenta una situación o escenas del Dos donde los amantes se incorporan a un proceso de desidentificación para alcanzar un conocimiento del mundo o una verdad.

La historia narra el recorrido existencial y personal de Evangelina Delgadillo, una mujer afectada por los aciagos años de la década de 1980 en la ciudad de Ayacucho, que luego de muchos años decide volver a su ciudad so pretexto de una desavenencia amorosa. Sin embargo, el verdadero motivo es el rencuentro con la memoria de los suyos, en especial la del amante desaparecido. Evangelina se presenta en la novela como una mujer afectada psicológicamente por el conflicto armado que asoló al Perú en los años ochenta. Su recorrido por la ciudad de Huamanga es el reencuentro con un espacio inexistente, posconflicto armado, donde la modernidad y la forma de vida de habitantes resultan siendo ajenos para ella. Casas, calles, iglesias, se presentan ante sus ojos lejos de la atmosfera tradicional del mundo andino donde vivió el amor inicial con su amigo Manuel Bajalqui. Sola, despojada del presente y con la mirada en el pasado, indaga dentro del manuscrito (entregado a un amigo policía de Manuel Bajalqui) sobre la verdadera identidad de su amante, quien para los estudiosos de la historia oficial es la encarnación del mal, un homo sacer, un asesino despiadado. No obstante, en la lectura del manuscrito del muchacho, Evangelina encuentra el testimonio de alguien que no intenta justificar en ningún momento los motivos que lo arrojaron a esta trágica guerra, sino la voz de un individuo cuya existencia vital estaba unida a la de su abuelo Gerardo, un campesino que lo orienta, a través de sus relatos y experiencias, en los temas más importantes de la vida, como lo es el amor.

Lo singular del manuscrito que acompaña los últimos días de Evangelina en la ciudad de Huamanga es que incorpora en sus páginas el testimonio 
de un sujeto que difiere totalmente de la versión oficial que se tiene de él. Si en el discurso de la CVR Manuel Bajalqui Curitumay es presentado como un ser insensible, una máquina de matar, un hombre ideologizado por ideas ortodoxas, el manuscrito muestra una visión más humana de este personaje. Por eso se narran pasajes de la vida del abuelo Gerardo, relatos orales de la comunidad y también momentos de la vida de Manuel. Habría que precisar la poca mención por parte del autor del manuscrito acerca de la relación amorosa que mantuvo con Evangelina. Lo que se conoce del idilio entre ambos se presenta en la novela desde la perspectiva de un grupo de amigos reunidos en un bar de la ciudad de Huamanga, los cuales, a través de un lenguaje lascivo y coprolálico, evocan a la Musa, Evangelina, y la relación que tuviera con Manuel. También la historia de amor es rememorada por la reflexión que sostiene Evangelina cuando transita por las calles de Ayacucho intentando explicar la naturaleza del manuscrito.

Finalmente, lo último que se conoce de Evangelina, según la versión del Sapo Irigoyen —el amigo policía que le entrega el manuscrito- es que la encontraron muerta en la habitación de la casa donde viviera con su hermano y su madre en los tiempos del conflicto armado, pero que ahora le pertenecía a otra familia.

\subsection{La escena del Dos: el encuentro de Manuel y Evangelina}

Lo primero que se debe mencionar es que en la escena del Dos convergen dos subjetividades disyuntas. En el caso del encuentro de Manuel Bajalqui y Evangelina Delgadillo, se trata de dos posiciones distintas que no están destinadas dentro del orden simbólico a estar juntas. Manuel es un muchacho del campo, de Pumaranra; en relación con Huamanga, que es la ciudad o la urbe, vendría a ser la periferia, lo segregado, lo marginal. En ese sentido, desde la perspectiva de los huamanguinos, representados por los amigos que liban cervezas en un bar, Manuel Bajalqui no pasa de ser un «paisano». O en voz de uno de los contertulios:

No sé por qué la sentía más cerca a nosotros que a las otras chicas, que parecían caminar con las naricitas respingadas, aun cuando muy pronto se pegó al paisano ese que vivía con su abuelo en la quinta Bajalqui. Debía de tener buen estómago ella, para enamorarse de ese huevón que venía no sé de qué puna de Víctor Fajardo. Se le pegó y no dio marcha atrás, para nadie (p. 12).

El desconcierto de los amigos surge porque Manuel Bajalqui no es de la ciudad de Huamanga, no comparte sus costumbres, sus hábitos; por el contrario, es de origen modesto, prácticamente un campesino cuyas maneras lo distancian de las personas que viven en la urbe. Habría que recordar que no hay nada en el encuentro o acontecimiento del amor que 
preestablezca que las identidades que participan en la escena del Dos deban ser semejantes; antes bien, el amor entendido como un encuentro convoca posiciones o subjetividades irremediablemente distintas. Esto se evidencia también cuando Narváez, otro de los amigos bebedores del bar, menciona que Evangelina —estando en condición de elegir a cualquier muchacho de la promoción y como mostrando su desprecio por todos los del barrio que deseaban estar con ella - «se mezcló con el paisano ese» (p. 13). Incluso, añade Narváez, «ni siquiera al pitucón de Caín Ruiz de Castilla le dio bola, eso que el pobre se chorreaba por ella» (p. 13).

En otro momento de la historia, ya cuando Evangelina Delgadillo andaba en salidas con Manuel, una de sus amigas le recrimina por refocilarse con su amigo en una pampita al aire libre:

Te agarraron como una chola, en el suelo. Te aplicaron un tumbaiquichu como a las pollerudas de su pueblo; en fin, la cabra siempre tira pal monte -me dijo Esperanza Kajat, quien siempre andaba aconsejándome que me alejara de Manuel porque era, según ella, un cholo apestoso (p. 299).

Es claro que dentro de la estructura mental de los huamanguinos, de los que viven en la ciudad, resulta ofensivo, incluso agraviante, andar en salidas con alguien que pertenezca al campo o uno de los pueblos olvidados de Ayacucho. Es por eso que mantener una relación con Manuel equivale a una suerte de afrenta cultural, pues lo correcto es que los miembros de la ciudad se mezclen entre ellos y los del campo hagan lo mismo. Cuando se producen estos encuentros disyuntos — desde la perspectiva de los huamanguinos-, una de las posiciones terminan por degradarse o convertida, como es el supuesto caso de Evangelina, en una «polleruda» o "amante de un cholo apestoso». Ya en este punto es clara la configuración de las posiciones que participan en el encuentro amoroso. Evangelina es una representante de la ciudad de Huamanga y, por tanto, ocupa un lugar privilegiado en relación con los habitantes del campo. La ciudad, en la novela de Julián Pérez, es un espacio «estridente, caótico, fugaz y esperpéntico como todos los espacios urbanos de la actualidad» (p. 21). Es el mundo de las falacias y de las quimeras, el mundo al que se llega, pero del cual no se regresa. Quienes ingresan a la ciudad terminan enajenados o discriminados, ya sea por las ventajas de la globalización o por los beneficios de la cultura letrada.

En cuanto a Manuel Bajalqui, como se dijo en líneas anteriores, su identidad o subjetivación se organiza a partir de su experiencia vital en el pueblo de Pumaranra y el aprendizaje que adquiere de la convivencia con su abuelo Gerardo. Mañuco es presentado en la novela como un adolescente tímido, ligado a la naturaleza, y luego como un hombre con una 
determinación inquebrantable. Bebe de las costumbres y de las creencias de su pueblo, conoce sus mitos y sus relatos, y no es ajeno a los problemas y debilidades que padecen su gente. Cuando está lejos de Pumaranra, lo extraña y añora su regreso para reencontrarse con su abuelo. $O$ en palabras del propio personaje: «mi patria es la quebrada andina de mi infancia, el crepúsculo serrano de bueyes, becerros y alfalfares» (p. 121). La posición de Manuel, como se dijo, está vinculada al campo, a la cosmovisión andina, y, por tanto, es marginal o periférica.

El amor permite ir más allá de las subjetividades personales o identidades disyuntas. Es por eso que se constituye como un encuentro o un acontecimiento donde los amantes van más allá de su individualidad; en otras palabras, aceptan las diferencias, que jamás serán Uno, pero descubren que sí es posible mirar el mundo desde la escena del Dos. En el caso de Evangelina Delgadillo, el encuentro del amor desestabiliza su visión del mundo anclado en los prejuicios citadinos y le permite concebir la realidad desde otra perspectiva:

Aun cuando había amigas que no aceptaban a los que eran de la ciudad, en mi caso no tuve problemas, acepté con todo y sus olores y sus colores y sus manías y sus costumbres a mi antiguo amigo, y los enarbolo incluso en la actualidad; tanto es así que me provoca esos deslices, esos lapsus con que me tiene atrapada aun hasta hoy (p. 285).

El acceso a la escena del Dos, como consecuencia del encuentro del amor, permite tener un conocimiento del mundo hasta ese entonces desconocido para los amantes. Evangelina descubre que la irremediable distancia que los separa no es un obstáculo para la realización de su amor. Que detrás de los olores, colores, manías y costumbres de su amigo emerge una verdad que agujera los saberes constitutivos, las opiniones, el lenguaje humano mortal. La verdad que se enuncia es que la distancia de la alteridad en lugar de alejarlos termina por acercarlos, paradójicamente, la dicotomía ciudad-campo, en lugar de ser una barrera, un obstáculo, es la condición para la puesta en marcha del encuentro amoroso, del acontecimiento que surge de la singularidad innominada. Por su parte, Manuel Bajalqui acepta, luego de reprocharse inicialmente su origen y sus costumbres provincianas, el haber «nacido y crecido en las agrestes serranías de las orillas del Pampas, acostumbrado tal vez, y no con mucha recurrencia, al suave olor a flor de dalia de las pareñitas y de las pumaranrinas jóvenes» (p. 328), así como la posibilidad de alcanzar el amor de Evangelina desde su diferencia, en lugar de enajenarse, convertirse en un joven de ciudad como los muchos, mantiene sus costumbres, su amor por la naturaleza, aunque después opta por incorporarse a un cuerpo político. Habría que precisar que tanto Evangelina como Manuel no tienen problemas para declarar su amor. Bajo 
el enunciado implícito «te amo», ambos deícticos, el yo y tú, afirman: «de lo que era un azar, yo voy a extraer otra cosa; voy a extraer una duración, una obstinación, un compromiso, una fidelidad» (Badiou, 2011, p. 60).

\subsection{Las pruebas y la duración del amor de Evangelina y Manuel}

El encuentro del amor está marcado por el azar que produjo «la escena del Dos» donde dos subjetividades distintas se vuelven una construcción del mundo desde la aceptación de las diferencias. No obstante, el amor no solo es un encuentro, una revelación, sino también una "duración», una forma de superación de las pruebas, de las crisis. La primera prueba a superar en el amor es la de ir más allá de la propia identidad: ese yo que busca sobreponerse al otro. El narcisismo. Habría que considerar ahora una situación del mundo, por ejemplo, el gusto de Manuel por la naturaleza. Ese gusto se incorpora al cuerpo de la verdad amorosa, a la escena del Dos, si en esa transferencia, Evangelina y Manuel no renuncian a su identidad. Es decir, el gusto o afecto personal no debe perder su fuerza con relación a las identidades de los amantes sino reevaluarse desde el punto del Dos. Esto permite enriquecer al amor y evitar caer en el goce narcisista: «porque me amas, debe gustarte la naturaleza». Para el caso de Evangelina Delgadillo, la muchacha aprende a observar la belleza de la naturaleza - los paisajes, los ríos, los animales-, no como una renuncia a su identidad citadina, no como una imposición del amor para conservarlo, sino como una reevaluación de que el mundo puede observarse también de otra manera. Esto último resulta significativo en la novela porque explica el apego de Evangelina por la naturaleza en la época de posguerra, ya que a través de ella rememora los momentos felices con Manuel.

En verdad, Huatatas no es un río; tal vez sí el Pongora, aunque también es pequeño en comparación a otros ríos, como el Pampas al que tanto se refería aquel entrañable amigo. Pero no sé qué encanto posee este riacho insignificante que está empozado en lo más hondo de mis paisajes interiores y me sigue de acá para allá, sin despegarse ni en los baches y sobresaltos en mis desplazamientos por conseguir la cuota necesaria para la subsistencia. Es posible que así sea porque, para ser explícita, yo vine una y otra vez aquí junto a mi amigo a lavar ropa (p. 68).

Lo que suplementa la naturaleza no es un elemento intrínseco de esta, el caudal del río, el remanso de sus aguas o todos sus meandros, sino la escena en la que los amantes experimentan el mundo como algo compartido en su disyunción, pues sus miradas aunque puestas en el mismo lugar nunca observan lo mismo. Es por eso que a Evangelina se le hace difícil interpretar el encanto de aquel riacho insignificante cuya belleza comparada a la de otros es inferior, porque en sí no reúne las características para considerarlo 
un verdadero río, como sí lo es el Pampas. No obstante, el Huatatas convoca la escena del Dos, donde Manuel y Evangelina experimentaron el mundo como un acto de solidaridad, de compañía, de hermandad. Esto ocasiona que la evocación de Evangelina en el presente se encuentre cargada de una potencia que la sobrepasa y la desestabiliza.

La duración, como se dijo, inventa una forma distinta de durar en la vida. En el caso del amor de Evangelina y Manuel, esta se vuelve a poner a prueba cuando ambos participan en la militancia política. Ya durante los años de estudiantes de secundaria en el colegio Mariscal Cáceres, tanto Manuel como Satuco Delgadillo, el hermano de Evangelina, participaban como miembros de la FUESA. Una vez dentro de la universidad, se convierten en activistas del grupo FER de la Facultad de Antropología. La novela ofrece algunas páginas donde se describe el proceso de subjetivación de Manuel Bajalqui, su conversión a un cuerpo político, así como su desidentificación en pos de la idea comunista ${ }^{5}$. En ese sentido, es importante indicar que la prueba por la que pasan Evangelina y Manuel no solo involucra la escena del Dos, sino también su vínculo con el mundo o el estado de la situación peruana. En otras palabras, a la prueba de los amantes con respecto a su dualidad, el nacimiento de los hijos, la rutina en el matrimonio, los celos enfermizos, se suma la incorporación política que, como se sabe, nunca está exenta a dudas e indecisiones.

Acepté el compromiso de apretujarme a sus sueños, más por conveniencia y curiosidad que por convencimiento, en las buenas y las malas; cosa que no logré cumplir y eso es lo que a estas alturas de mi vida se ha convertido en mi perturbación permanente. Aunque eso mismo juegue a su favor puesto que no me permite olvidarlo de una vez por todas (p. 93).

Una vez puesto en marcha el amor, hay que procurar su duración, vencer las pruebas, las crisis, para el caso de la Manuel y Evangelina, considerar que el Dos convocado en el encuentro de ambos se extienda o anude lo genérico de la política, ya que el amor enlaza las cuatro singularidades de donde advienen las verdades (la ciencia, el arte, la política y el amor). Como señala Badiou (2002, p. 259), «lo esencial, es que el amor, lo he dicho, es el garante de lo universal, puesto que él elucida la disyunción como simple ley de una situación». Ya se dijo que la disyunción es la condición del encuentro, porque jamás observaremos el mundo desde los ojos del ser amado. Es en ese contexto que el compromiso político, por más que congregue a los amantes bajo la «ldea», nunca será interiorizado de la

5 La descripción del proceso de subjetivación del personaje Manuel Bajalqui es desarrollado con mayor amplitud en la tesis de la cual se extrajo este artículo. 
misma forma. Así, la fidelidad adquiere modalidades distintas; en algunos casos, como el de Manuel Bajalqui, participar de la revolución significa comprometer su existencia material y simbólica, al punto de convertirse, bajo el discurso oficial del CVR en un homo sacer. En el caso de Evangelina Delgadillo, su fidelidad, aunque contingente -ella se considera una zorra andina porque no aceptó el compromiso político y sus consecuencias, como sí lo hizo Manuel, $y$, ante la primera arremetida de los hechos violentos, escapó de Huamanga-, se aboca a indagar en lo que significó el conflicto armado y demostrar la humanidad de su amado.

Considerando las dos orientaciones de la fidelidad, en la política y el amor, la «duración» de la segunda se atestigua en la persistencia y fidelidad de Evangelina por tratar de recobrar la memoria de Manuel. El manuscrito se convierte en una singularidad, pues reorganiza la realidad presentando nuevas imágenes del conflicto armado, que, sin explicitar los hechos, sin aludir al referente, a las matanzas, al fuego cruzado, a los levantamientos y represiones, indaga en la humanidad de la cual fueron despojados quienes participaron del bando de los alzados.

\section{Conclusiones}

El análisis metatextual sobre el tópico del amor en la narrativa de Julián Pérez incurre, como se demostró, en una suerte de fijación entre la triada amor, sexo y erotismo. En ese sentido, prioriza el valor de las relaciones sexuales en la representación ficcional del mundo andino generando una gradación leída como logro estético.

El análisis de la novela Criba, de Julián Pérez, demuestra el carácter afirmativo del amor, el cual trasciende las relaciones sexuales a través de la aceptación de las diferencias. Esto se corrobora en el «encuentro» de los personajes Evangelina Delgadillo y Manuel Bajalqui Curitumay, quienes se incorporan en la Escena del Dos para luego persistir en la «duración» del amor.

Finalmente, la incorporación de los aportes filosóficos de Alain Badiou en los estudios literarios permitiría un viraje del tópico del amor en la narrativa peruana.

\section{Contribuciones}

Amancio Edison Flores Muñoz ha participado en la concepción del artículo, la recolección de datos, su redacción y aprobación de la versión final.

\section{Fuente de financiamiento}

Autofinanciado.

\section{Conflicto de interés}

El autor declara no tener conflictos de interés. 


\section{REFERENCIAS BIBLIOGRÁFICAS}

Badiou, A. (1999). San Pablo: La fundación del universalismo. Barcelona: Antropos.

Badiou, A. (2002). Condiciones. Ciudad de México: Siglo XXI.

Badiou, A. (2004). La ética. Ciudad de México: Herder.

Badiou, A. (2005). Imágenes y palabras: escritos sobre cine y teatro. Buenos Aires: Manantial.

Badiou, A. (2007). El ser y el acontecimiento. Buenos aires: Manantial.

Badiou, A. (2008). Lógicas de los mundos: el ser y el acontecimiento 2. Buenos Aires: Manantial.

Badiou, A. (2010). Segundo manifiesto por la filosofía. Buenos Aires: Manantial.

Badiou, A. (2011). Elogio del amor. Madrid: La Esfera de los Libros.

Bajtín, M. (1982). Estética de la creación verbal. Ciudad de México: Siglo XXI.

Bajtín, M. (1989). Teoría y estética de la novela. Madrid: Taurus.

Escajadillo, T. (1994). La narrativa indigenista peruana. Lima: Amaru.

Gutiérrez, M. (2007). El pacto con el diablo. Ensayos 1966-2007. Lima: San Marcos.

Lozano, M. (2004). El amor como experiencia de verdad: de Platón a Badiou. Avatares Filosóficos, 1, pp. 199-207. Recuperado de http://revistas. filo.uba.ar/index.php/avatares/article/view/249/159.

Pérez, J. (2019). Criba. Lima: Penguin Random House.

Žižek, S. (1992). El sublime objeto de la ideología. México: Siglo XXI.

Žižek, S. (2000). Mirando el sesgo: una introducción a Jacques Lacan a través de la cultura popular. Buenos Aires: Paidós.

Žižek, S. (2001). El espinoso sujeto: el centro ausente de la ontología política. Barcelona: Paidós. 